\title{
Intention to Use Behavioral Health Data From a Health Information Exchange: Mixed Methods Study
}

Randyl A Cochran ${ }^{1}$, PhD; Sue S Feldman ${ }^{2}, \mathrm{RN}, \mathrm{MEd}, \mathrm{PhD}$; Nataliya V Ivankova ${ }^{2}, \mathrm{MPH}, \mathrm{PhD}$; Allyson G Hall ${ }^{2}$, PhD; William Opoku-Agyeman ${ }^{3}, \mathrm{MSc}, \mathrm{MPH}, \mathrm{PhD}$

\footnotetext{
${ }^{1}$ Department of Health Sciences, College of Health Professions, Towson University, Towson, MD, United States

${ }^{2}$ Department of Health Services Administration, School of Health Professions, University of Alabama at Birmingham, Birmingham, AL, United States

${ }^{3}$ School of Health and Applied Human Sciences, College of Health and Human Services, University of North Carolina Wilmington, Wilmington, NC, United States
}

\section{Corresponding Author:}

Randyl A Cochran, PhD

Department of Health Sciences

College of Health Professions

Towson University

8000 York Road

Linthicum Hall 121C

Towson, MD, 21252

United States

Phone: 14107042345

Email: rcochran@towson.edu

\section{Abstract}

Background: Patients with co-occurring behavioral health and chronic medical conditions frequently overuse inpatient hospital services. This pattern of overuse contributes to inefficient health care spending. These patients require coordinated care to achieve optimal health outcomes. However, the poor exchange of health-related information between various clinicians renders the delivery of coordinated care challenging. Health information exchanges (HIEs) facilitate health-related information sharing and have been shown to be effective in chronic disease management; however, their effectiveness in the delivery of integrated care is less clear. It is prudent to consider new approaches to sharing both general medical and behavioral health information.

Objective: This study aims to identify and describe factors influencing the intention to use behavioral health information that is shared through HIEs.

Methods: We used a mixed methods design consisting of two sequential phases. A validated survey instrument was emailed to clinical and nonclinical staff in Alabama and Oklahoma. The survey captured information about the impact of predictors on the intention to use behavioral health data in clinical decision making. Follow-up interviews were conducted with a subsample of participants to elaborate on the survey results. Partial least squares structural equation modeling was used to analyze survey data. Thematic analysis was used to identify themes from the interviews.

Results: A total of 62 participants completed the survey. In total, 63\% $(n=39)$ of the participants were clinicians. Performance expectancy $(\beta=.382 ; P=.01)$ and trust $(\beta=.539 ; P<.001)$ predicted intention to use behavioral health information shared via HIEs. The interviewees $(n=5)$ expressed that behavioral health information could be useful in clinical decision making. However, privacy and confidentiality concerns discourage sharing this information, which is generally missing from patient records altogether. The interviewees also stated that training for HIE use was not mandatory; the training that was provided did not focus specifically on the exchange of behavioral health information.

Conclusions: Despite barriers, individuals are willing to use behavioral health information from HIEs if they believe that it will enhance job performance and if the information being transmitted is trustworthy. The findings contribute to our understanding of the role HIEs can play in delivering integrated care, particularly to vulnerable patients.

(JMIR Ment Health 2021;8(5):e26746) doi: $\underline{10.2196 / 26746}$

\section{KEYWORDS}

behavioral health; integrated care; health information exchange; behavioral intention; patient care; mixed methods research 


\section{Introduction}

\section{Background}

Behavioral health conditions adversely affect an individual's well-being, quality of life, and life expectancy. Behavioral health conditions are defined as mental illnesses (eg, depression, anxiety, schizophrenia, and bipolar disorder) and substance use disorders that impair the functioning of an individual [1]. Patients with these conditions require the delivery of team-based care to achieve optimal health outcomes [2,3]. Nearly half of the adult population will meet the criteria for a mental illness during their lifetime [4]. Recent projections indicate that in the United States, approximately $19 \%$ of the adult population may have a mental illness at any point in time [5-7]. Behavioral health conditions are expected to surpass chronic medical conditions to become the leading cause of disability worldwide [8], with depression alone projected to become the second most prevalent cause of disability [7].

The relationship between physical health and mental health is complex [9-11]. Patients diagnosed with a behavioral health condition frequently have chronic medical comorbidities [4,5,12-15]. The association of mental illness with chronic disease contributes to the inefficient use of health care services (eg, increased inpatient hospital utilization) [5,16-18]. Other factors such as infrequent use of primary care and preventive services, poor chronic disease management, and the use of antipsychotic medications [19-23] also contribute to the overutilization of hospital services. Patients with behavioral health conditions, coupled with chronic medical comorbidities, contribute substantially to health care spending. A population-based cohort study in Alberta, Canada, revealed that patients with a chronic medical illness and a co-occurring mental health condition had a higher mean of 3-year adjusted health care costs (Can $\$ 38,250$ [US $\$ 31,700$ ]) than chronically ill patients without a mental health condition (Can \$22,250 [US $\$ 18,440]$ ] [24]. A similar pattern is expected in the United States. In fact, the costs are likely to be higher [25]. The costs alone indicate that it is both financially and clinically prudent to consider new ways to manage behavioral health conditions in chronically ill patients [25]. A novel approach to control costs is a coordinated care delivery system.

Behavioral health patients require coordinated care but often fail to receive it $[17,26]$. This level of care requires better communication and information sharing between general medical and behavioral health care providers. Therefore, it is necessary to develop new approaches that facilitate the effective treatment of both medical and behavioral health conditions [27]. Health information exchanges (HIEs), a component of health information technology (IT), can facilitate the integration of different health care services provided to behavioral health patients with chronic conditions.

HIEs are organizations that enable the digital exchange of health-related data [28], and they are one type of health IT thought to facilitate such integration. The exchange of health information through HIEs has many benefits, including safer, more efficient care that effectively manages both the behavioral and physical health needs of individual patients [13,29-31].
HIEs lead to efficient information sharing between providers in emergencies that require prompt, accurate diagnosis and treatment [29]. The effectiveness of HIEs has been studied in care coordination in general, especially in chronic disease management, but there are few studies that examine HIEs in the context of behavioral health [6,32-35]. The dearth of studies in behavioral health and HIE is a result of rising challenges with behavioral health data. Specifically, there is a disjoint between the clinical language, codes, and data reporting between behavioral health and general medicine among providers [6]. In addition, federal regulations complicate behavioral health information sharing. One of these regulations, that is, Section 42 Part 2, was adopted in the Code of Federal Regulations (42 CFR Part 2) in 1972 to ensure privacy protection for individuals receiving treatment for substance use disorders. It prohibited the disclosure of records related to substance use treatment without express authorization from the patient (with certain exceptions in emergency situations) [36]. Revisions of 42 CFR Part 2 in 2017 and 2018 have aimed to modernize the regulation and to facilitate the integration of behavioral health in general medical settings. Despite these efforts, challenges remain $[6,36]$. Taken together, these factors create barriers to exchanging behavioral health information and delivering integrated care for this patient population.

Therefore, the aim of this study is to identify and describe various factors that may influence health care providers' intention to use and actual use of behavioral health information obtained from an HIE. This is accomplished by using a mixed methods approach guided by the theoretical backdrop of the unified theory of acceptance and use of technology (UTAUT) and diffusion of innovation (DOI). This study addresses the following research questions:

1. What factors are associated with the intention to use behavioral health information obtained from HIEs?

2. From the perspective of health care providers, what are the facilitators of and barriers to behavioral health information use from HIEs?

\section{Literature Review and Conceptual Framework}

Integrated behavioral health care has demonstrated effectiveness in treating patients with behavioral health disorders and co-occurring medical conditions $[37,38]$. Such models of care delivery can improve the quality of care by delivering treatments that align with the clinical needs of patients [38]. A systematic review revealed that among 4 randomized controlled trials, 2 of the studies showed minor improvements in physical health, whereas the other 2 studies showed no significant changes in physical health [39]. Furthermore, improvements in seeking preventive care were also observed. However, none of these studies examined the effect of these interventions on functional or clinical outcomes [39]. Improvements in both access and quality of care have been attributed to communication and information sharing between clinicians, particularly when treating patients with complex medical and behavioral needs [40]. This finding suggests that establishing effective communication channels is crucial for the success of integrated care delivery models. However, there are barriers to 
communication between medical and behavioral health care providers.

A 2011 study examined the perspectives of behavioral health care providers regarding the benefits and barriers of HIE utilization [41]. According to the study, behavioral health care providers stated that the use of HIEs would (1) improve the quality of care and communication between different types of providers, (2) increase cost and time burdens, (3) raise concerns related to access to and vulnerability of patient and client information, and (4) impact workflow and control. Similarly, a 2019 qualitative study explored the perspectives of patients with mental health conditions to gain an understanding of privacy in the context of exchanging personal health information [42]. All 14 participants acknowledged the importance of privacy in health care, particularly concerning information related to sensitive diagnoses (eg, mental health conditions). However, the degree of concern varied and was most frequently related to negative experiences and perceptions related to privacy. The interviewees expressed that, overall, they trusted that health care professionals and organizations would take appropriate measures to protect the privacy of information related to mental health diagnoses. The participants were largely uninformed about existing policies and regulations designed to protect the privacy of mental health information, and those who had negative experiences related to privacy expressed doubt about the effectiveness of these regulations. However, the participants acknowledged that the electronic exchange of health information was a practical approach to ensuring high-quality patient care. It is important to note that this study was conducted in Canada, where a single-payer system exists.

The 2 theories that are deemed appropriate to explore our overall research questions are the UTAUT and the DOI theory.
UTAUT integrates constructs from earlier IT adoption theories to examine their influence on individuals' intentions to use technology and the subsequent use of the technology [43]. UTAUT explains nearly $70 \%$ of the variance related to the intention to use technology [44]. The original UTAUT model attributes behavioral intention and subsequent technology use to 4 main constructs: (1) performance expectancy (perceptions of the ability of the technology to assist in meeting job-related goals), (2) effort expectancy (ease of use of technology), (3) social influence (perception that important figures support the use of technology), and (4) facilitating conditions (infrastructure that supports the use of technology) $[43,45]$. Extensions of the UTAUT model have considered the influence of additional factors on behavioral intention to use technology, such as trust and perceived risk [46].

DOI examines 5 factors that determine the rate of adoption of a new technology (innovation) within an organization: (1) relative advantage (the innovation is perceived as a better solution than its predecessor), (2) compatibility (the innovation fits with the organization's culture and norms), (3) complexity (the innovation is easy to understand and use), (4) trialability (individuals can experiment with innovation before adoption), and (5) observability (the results of using the innovation are visible to others) $[47,48]$. The trialability construct was extracted from this theory because it was not captured in the UTAUT framework. The exchange of behavioral health data via an HIE is a relatively novel concept, and it is possible that pilot testing this type of data exchange could influence behavioral intention. The conceptual model for this study, which is derived from these 2 theories, is shown in Figure 1. The research questions were identified using this model.

Figure 1. Conceptual model.

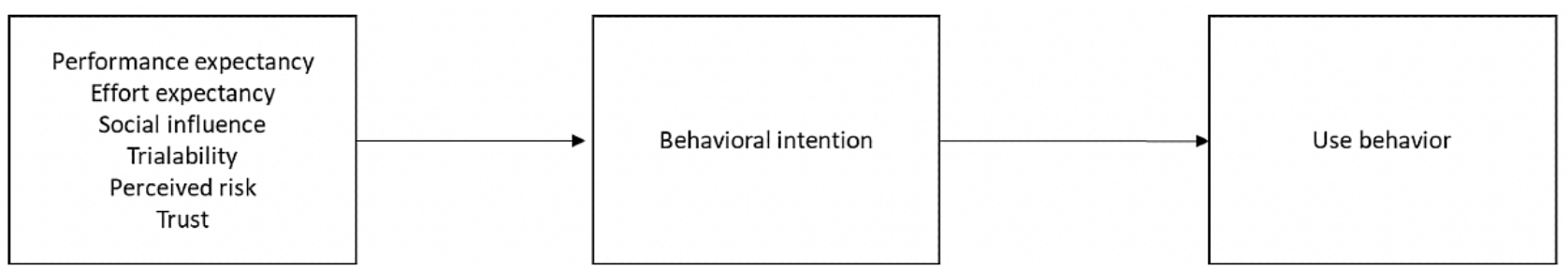

\section{Methods}

\section{Overview}

A sequential explanatory mixed methods design was used in this study. This mixed methods design enables researchers to provide more thorough explanations of the trends that emerge from the quantitative phase of the study by further exploring participants' perspectives $[49,50]$. The quantitative and qualitative study phases are described in the following sections.

\section{Quantitative Phase}

\section{Sampling}

Survey participants were selected through convenience sampling. Alabama and Oklahoma were selected for participation because both these states have established HIEs and reported making some efforts to incorporate behavioral health data into patient records. General medical care providers (physicians, nurses, and physician assistants) and nonclinical staff (directors, network administrators, and patient experience representatives) were identified as potential participants.

\section{Data Collection}

A validated survey instrument was emailed to clinicians and staff in Alabama and Oklahoma [45,46]. The survey prompt and questionnaire items are provided in Multimedia Appendix 1. The influence of several predictors was examined through the conceptual model developed for the study: (1) performance expectancy, (2) effort expectancy, (3) social influence, (4) perceived risk, (5) trust, and (6) trialability. The first 5 constructs were derived from the UTAUT model [45]. The sixth construct, trialability, was derived from the DOI model $[47,48]$. The 6 constructs from the UTAUT and DOI frameworks were the independent variables for this study. 
The final survey was adapted from the UTAUT questionnaire items developed by Venkatesh et al [45]. Two of the researchers ( $\mathrm{RC}$ and SF) developed, pilot tested with 4 respondents not involved in the study, and refined the survey (eg, question order and wording) before it was administered to the study sites. The survey used in this study contained statements related to each construct. Respondents expressed their level of agreement with each statement using a 7-point Likert scale, with 1 being Strongly agree and 7 being Strongly disagree. The constructs within the conceptual model have been found to have high reliability and validity in previous studies: standardized factor loadings and average variance extracted values exceeded the recommended threshold of $0.50[46,51,52]$. Furthermore, the composite reliability values were above 0.90 for each of the constructs, surpassing the minimum recommended value of $0.70[46,53]$. Similar findings have emerged for the behavioral intention construct [46]. Preliminary analysis of the survey data collected for this study also met the recommended thresholds for reliability and validity.

An initial prompt to participate in the survey was sent via email. The prompt briefly described the study (eg, purpose, procedures, risks, and benefits). In addition, the prompt included a link to the web-based survey and a consent form that provided more details about the study. Data collection began on June 4, 2018, and ended on August 14, 2018.

\section{Variables}

Behavioral intention was the outcome of the combination of the independent variables. It was also a predictor of use behavior. Similar to the independent variables, behavioral intention was operationalized as an ordinal-level variable. Survey items related to behavioral intention were answered using the same 7-point Likert scale adopted for the independent variables.

Use behavior was operationalized as a dichotomous variable. Participants answered Yes or No to the initial screening question: "Have you ever used behavioral health information obtained from the HIE your organization uses?" Participants who responded Yes answered questions related to performance expectancy, effort expectancy, social influence, perceived risk, and trust. Participants who responded No answered an additional set of questions pertaining to trialability. On the basis of the response to the initial screening question, the wording of the subsequent questions was modified to reflect actual experiences versus perceptions of obtaining behavioral health information from the HIE.

Finally, the survey instrument included questions designed to collect demographic information, which included data related to gender, education, job title, age, race or ethnicity, and level of comfort and experience with technology. This study was conducted with the approval of the University of Alabama at Birmingham IRB \#300001017.

\section{Data Analysis}

For the survey data, preliminary descriptive statistics were generated. Furthermore, we tested the reliability and validity of the survey items. We used partial least squares structural equation modeling (PLS-SEM) to test the relationships between the constructs in the conceptual model. PLS-SEM is a nonparametric alternative to covariance-based structural equation modeling, which makes it more applicable to this study, as we have a small sample and data that are not normally distributed [54-57]. PLS-SEM can be used in both exploratory and confirmatory studies [58]. All statistical analyses were performed using Stata version 15 at an $\alpha$ level of .05.

\section{Qualitative Phase}

\section{Sampling}

Semistructured interviews were conducted with a subsample of the survey participants to better understand the role of these factors from the subjects' perspectives and to discover any additional factors that were not captured in the survey. A total of $18 \%(11 / 62)$ survey participants provided their contact information for a follow-up interview at the end of the quantitative survey. Of these, 5 completed the interviews.

\section{Interview Guide}

Three of the authors (RC, SF, and NI) collaborated on the development of the interview guide for this phase. The interview questions were developed to elaborate on predictors of intention to use behavioral health information from an HIE that emerged from the initial quantitative survey. Therefore, the interview guide was designed to facilitate a closer examination of the constructs from the UTAUT and DOI frameworks. Likewise, the interview questions also captured information about findings that were contradictory to previous research to better understand the emergence of these inconsistencies [59]. Before deployment, the interview guide was pilot tested with 4 individuals with expertise in health informatics $(n=3)$ and psychiatric nursing $(n=1)$. Minor revisions were made to the wording and ordering of the interview questions. Multimedia Appendix 2 provides the final interview guide.

\section{Data Collection}

The first author $(\mathrm{RC})$ conducted the interviews with the survey respondents. An initial request for interview email was sent to the participants, and follow-up emails were sent 2 and 4 weeks after the initial request. Interviews were conducted either in person or via teleconference (Zoom), based on interviewee preference and timing. All interviews were recorded and transcribed using the Otter Voice Notes mobile app. The interviews were conducted from March 19 to May 2, 2019.

\section{Data Analysis}

Verbatim interview transcripts were analyzed using inductive and deductive thematic analysis with NVivo 12. The development of the interview questions was partially guided by the constructs in the conceptual model; additional themes were derived from the content within the interview transcripts [60]. The following 4-stage analytical process was adopted for the study: (1) becoming familiar with data, (2) generating themes by aggregating coded segments of data, (3) creating comparative categories, and (4) revising and refining the themes [61]. Two of the authors ( $\mathrm{RC}$ and $\mathrm{SF}$ ) engaged in peer debriefing to discuss the interview process and the resulting themes, thus generating additional insights into the interview findings [62]. To increase the trustworthiness of data, we used member checking: 
participants received a 1- to 2-page summary of the interview transcript from the interviewee (RC) by email and were asked to provide clarification or ask additional questions. Of the 5 participants, 2 responded to the follow-up email. One participant provided additional clarification for one of the discussion points; the other participant found no errors in the summary document. Quantitative and qualitative findings were further integrated to create meta-inferences using a joint display [63].

\section{Results}

Due to the sequential nature of this mixed methods study design, we present the results in sequence: quantitative findings followed by qualitative findings and then followed by the integration of quantitative and qualitative findings.

\section{Quantitative}

\section{Descriptive Statistics}

Descriptive statistics of the survey participants are presented in Table 1. A total of $90 \%$ (56/62) of the respondents reported that they did not exchange behavioral health data via the HIE. A majority of the respondents $(49 / 62,79 \%)$ were female, and $83 \%$ $(52 / 62)$ of the respondents were aged between 30 and 59 years. A large proportion of the health care providers in this sample were identified as nurses $(27 / 62,44 \%)$. Nonclinical roles $(23 / 62$, $37 \%$ ) consisted of directors, network administrators, and patient experience representatives. With regard to the reported level of computer experience, most participants $(45 / 62,72 \%)$ identified as average users. 
Table 1. Descriptive statistics of behavioral health information exchange survey participants $(\mathrm{N}=62)$.

\begin{tabular}{ll}
\hline Variables & Values, $\mathrm{n}(\%)$
\end{tabular}

\section{Retrieved behavioral health data from their organization's HIE ${ }^{\mathrm{a}}$}

Yes

No

Gender

Female

Male

Prefer not to state

$1(2)$

\section{Age group (years)}

21-29

30-39

40-49

$18(29)$

50-59

$16(25)$

60-69

$\geq 70$

$1(2)$

Job title

Nurses

Physicians

10 (16)

Physician's assistants

Others

Education

High school diploma or GED ${ }^{\mathrm{b}}$

Some college

2-year degree

4-year college degree

Master's degree

$10(16)$

Professional degree

Doctorate

Hispanic or Latino origin

Yes

No

Race

American Indian or Alaska Native

Asian

Black or African American

White

Other

Level of computer experience

\section{Novice}

Average

Advanced

$16(26)$

${ }^{\mathrm{a}} \mathrm{HIE}$ : health information exchange. 
${ }^{\mathrm{b}}$ GED: general education development.

\section{Measurement Validity}

The measurement model determined the reliability and validity of the survey items associated with each latent construct in the conceptual model. Cronbach $\alpha$ scores of .7 or higher indicate internal consistency $[64,65]$. The measurement model is illustrated in Multimedia Appendix 3. With the exception of one item on the performance expectancy construct, all items met the criteria for internal consistency.

\section{PLS-SEM Results}

The results of PLS-SEM are presented in Table 2. The standardized path coefficients $(\beta)$ denote the strength and direction of the relationship between the constructs in the conceptual model.

Table 2. Path analysis of the constructs within the conceptual model.

\begin{tabular}{lll}
\hline Predictors of intention to use behavioral health information from the HIE ${ }^{\mathrm{a}}$ & $\beta^{\mathrm{b}}$ & $P$ value \\
\hline Performance expectancy & .382 & .01 \\
Effort expectancy & .055 & .72 \\
Social influence & -.043 & .72 \\
Perceived risk & .061 & .47 \\
Trust & .539 & $<.001$ \\
Trialability & .093 & .34 \\
Use behavior & .127 & .68 \\
\hline
\end{tabular}

${ }^{\mathrm{a}} \mathrm{HIE}$ : health information exchange.

$\mathrm{b}_{\mathrm{B}}$ represents the standardized path coefficients from the partial least squares structural equation modeling results. The standardized path coefficients indicate the strength and direction of the relationship between the constructs.

The PLS-SEM results revealed that performance expectancy and trust are the significant predictors of behavioral intention to exchange behavioral health information via HIEs. On average, survey participants who reported higher scores on the performance expectancy measures also reported higher scores on the behavioral intention measures ( $\beta=.383 ; P=.01)$. Similarly, participants who scored higher on the trust measures also had higher scores on the behavioral intention measures $(\beta=.539$; $P<.001)$. In this study, trust was found to be the strongest predictor of behavioral intention. Furthermore, behavioral intention was not significantly associated with the actual use of behavioral health information from HIEs.

\section{Qualitative}

\section{Interview Participants and Overview}

Of the 5 individuals who participated in the interviews, only 1 was employed in Oklahoma. The majority of the participants were nonclinical employees, with only 1 participant (a nurse practitioner) involved in direct patient care. The length of the interviews ranged from 19 minutes to 60 minutes, with an average interview length of 34 (SD 16) minutes.

\section{Themes From the Interviews}

A total of 6 themes emerged from the interviews: (1) usefulness of behavioral health information in care delivery, (2) regulations restricting behavioral HIE, (3) behavioral health and stigma, (4) missing or difficult-to-locate behavioral health data, (5) lack of mandatory training for behavioral HIE, and (6) future utilization of the HIEs. Each theme is explored in detail in the following sections. More details about each theme and the related participants' quotes are given in Multimedia Appendix 4.

\section{Usefulness of Behavioral Health Information in Care Delivery}

Sharing behavioral health information can improve care delivery. In various settings, exchanging health data via an HIE increases efficiency. More specifically, exchanging behavioral health information in an emergency department could help the attending physician to become familiar with a patient's medical history and could be used in discharge planning. Despite these perceived benefits, there are several barriers that prohibit the exchange of behavioral health information.

\section{Regulations Restricting Behavioral HIE}

Existing regulations and policies make behavioral HIE challenging. One of the most significant perceived barriers to behavioral HIE, 42 CFR Part 2, makes health care workers hesitant to share sensitive information electronically. 42 CFR Part 2 leaves room for interpretation with regard to the exchange of behavioral health information, and it is not uncommon for health care administrators to err on the side of caution.

Overall, the participants expressed doubt that behavioral HIE will become a common practice in the near future, given the influence of 42 CFR Part 2. The restrictions surrounding the exchange of behavioral health information will most likely discourage the sharing of this information, unless it is deemed essential to the provision of care. Even with the recent relaxation of 42 CFR Part 2, one interviewee specifically stated that behavioral health data will never be effectively shared via HIE: "[42 CFR Part 2] simply discourages it." 42 CFR Part 2 was enacted as a response to the stigma surrounding sensitive diagnoses, including those related to behavioral health. This stigma persists even today. 


\section{Behavioral HIE and Stigma}

Stigma continues to surround behavioral health conditions and contributes to the suppression of behavioral health information in medical records. As such, mental illness continues to be considered taboo, and because of this, information related to a mental health diagnosis is often separated from the rest of a patient's medical record. Furthermore, the existing stigma may discourage patients from revealing their diagnoses to a new health care provider. This hesitation to disclose this information hinders the flow of health-related information and complicates the delivery of appropriate care, especially if the provider is unfamiliar with the patient's medical history.

\section{Missing or Difficult-to-Locate Behavioral Health Information}

One of the concerns raised about incorporating behavioral health information into the electronic medical record was centered on locating the information within the HIE. One interviewee suggested that if behavioral health information is difficult to identify, it could reduce efficiency in care provision. In addition, removing behavioral health patients' records from the HIE further complicates the delivery of appropriate care.

General medical practitioners who access the HIE do not specifically look for behavioral health information. As such, participants do not know where this information would be located within the patient records. A participant (interviewee 4) suggested that it might be beneficial to provide training to assist health care providers in identifying behavioral health information in the patient record. Adequate training could not only reduce the potential workflow issues associated with behavioral HIE but could also facilitate the provision of appropriate care.

\section{Lack of Mandatory Training for Behavioral HIE}

The local network administrator for the Alabama site (interviewee 2) trained participants on the proper use of the HIE. There was no component of the training that focused exclusively on the exchange of behavioral health information via the HIE. The training encompassed basic functions (eg, how to $\log$ in, what information can be found within the system, and where to locate it). The training provided was not mandatory. In fact, some participants learned about HIEs via word of mouth. One participant (interviewee 4) believed that providing formal training could allow care providers to provide input regarding the usefulness of clinical data. Likewise, the training could help them to understand why there are restrictions on exchanging certain types of clinical data, such as behavioral health information.

The lack of mandatory training for HIE use made it challenging for providers to figure out how to integrate behavioral health information. However, the interviewees expressed hope that they will be able to increase the utilization of HIEs in the future.

\section{Future Utilization of HIEs}

The interviewees acknowledged the value of exchanging general health data across HIEs and hoped to increase their utilization in the near future. Some participants also saw value in using the systems to exchange behavioral health information between multiple providers, despite the numerous barriers that currently exist. One participant (interviewee 4) suggested that these HIEs might be necessary to provide effective treatment in appropriate care settings to these difficult-to-treat patients.

\section{Integration of the Quantitative and Qualitative Findings}

We further integrated the quantitative and qualitative findings using a joint display. The joint display enabled us to compare the quantitative and qualitative results, explain similarities and differences between the findings, and develop meta-inferences regarding the exchange of behavioral health information via an HIE (Multimedia Appendix 5). In summary, the participants stated that having access to a patient's full medical record, including behavioral health diagnoses, would be useful in delivering appropriate treatment. Despite the potential benefits of having access to this information, there are several barriers that prohibit the exchange of behavioral health information. These barriers are primarily related to technical capabilities, policies and regulations, stigma, and training. Even with these challenges, the interviewees acknowledged the value of having complete information and expressed some hope that behavioral HIE will become standard practice in the future.

\section{Discussion}

\section{Principal Findings}

The purpose of this mixed methods study is to identify and describe factors that may influence the intention to exchange and use behavioral health information obtained from an HIE. The preliminary findings from the quantitative phase of the study indicate that performance expectancy and trust are significant predictors of behavioral intention to exchange behavioral health information via HIEs. In other words, participants believed that exchanging behavioral health information via HIEs would improve their job performance. However, $90 \%$ (56/62) of survey participants reported that they did not use HIEs to exchange behavioral health information, which likely contributed to the insignificant association between behavioral intention and actual use. The misalignment between performance expectancy and behavioral intention is supported in the literature $[66,67]$. One explanation for this finding is that understanding the potential job-related benefits of using a technology might not motivate health care professionals to adopt it if there are other contextual factors to consider [67].

Within health care, trust is a predictor of the intention to use technology among both patients and physicians [68,69]. Our findings were consistent with the literature in that participants suggested that the lack of full disclosure of behavioral health conditions, possibly due to stigma, may produce an incomplete record and not provide practitioners with valuable clinical information at the point of care.

In summary, 2 constructs (performance expectancy and trust) emerged as significant predictors in the initial quantitative phase of the study. One theme (usefulness of behavioral health information in care delivery) emerged from qualitative interviews that provided further insights into the significance of the performance expectancy construct. However, there were several divergent findings. Perceived risk did not emerge as a 
significant predictor in the quantitative phase; however, the interviewees stated that regulations and stigma are barriers to behavioral HIE. The interviewees suggested some connection between trust and stigma of behavioral health diagnoses. One interviewee stated that people were hesitant to disclose behavioral health information; therefore, the information that could truly be helpful at the point of care is often missing in terms of behavioral health (interviewee 1). Trialability did not emerge as a significant predictor of behavioral intention in the quantitative phase; however, the interviewees discussed a lack of in-depth training in the subsequent qualitative phase. Finally, behavioral intention was not a significant predictor of the actual use of HIEs for the purpose of behavioral HIE. This is likely due to the fact that participation in behavioral HIE efforts at these 2 study sites is low. However, interviewees expressed hope that in the future, HIEs will be used to exchange the full patient record, including any behavioral health diagnoses or treatment.

\section{Implications and Future Research}

As behavioral health becomes a growing public health concern, health care practitioners have largely accepted the need for integrated care [70,71]. Early integrated care models have shown improvements in patients' mental and physical health [71-74]. In addition, health care providers have expressed the belief that omitting behavioral health data from patient records hinders their ability to make appropriate treatment recommendations [71]. The findings of this study provide additional support to these notions.

The successful delivery of integrated care requires a reconsideration of existing policies and regulations as well as the establishment of clear guidelines and best practices for handling sensitive health-related information [75]. In the wake of the COVID-19 pandemic, restrictions on the sharing of personal health information have been relaxed. The requirement to obtain patient consent may be waived if the provider determines that there is a bona fide medical emergency [76]. It is crucial for stakeholders to consider whether this regulatory change should be retained following the pandemic.

\section{Limitations}

Although the findings are valid in the context of this study, the small sample size may limit its generalizability. This is a common limitation of studies that are conducted during early uses of IT, thus necessitating the use of nonparametric methods such as PLS-SEM [77]. With the exchange of behavioral health data via HIE being relatively nascent (at the time of this study), this limitation is expected. Furthermore, the relationships between these constructs cannot be deemed causal but rather provide some insights into perceptions and reality. Similarly, because there were few participants who exchanged behavioral health information via HIEs, there was not enough variation in the responses to determine whether there were different sets of predictors for those who used the HIEs to exchange behavioral health information and those who did not. It is possible that the use of convenience sampling contributed to the homogeneity in the responses. However, the lack of active participants in behavioral HIE efforts could also be partially explained by the novelty of both the Alabama and Oklahoma HIEs.

Even in light of these limitations, the findings provide early positive suggestions for the use of behavioral health data shared by HIEs. This study is the first to adopt a mixed methods approach to examine the use of HIEs to share patients' behavioral health information. The use of mixed methods allowed the researchers to identify and explore factors that may influence the adoption and use of HIEs to facilitate behavioral HIE. This study was conducted across multiple states. Finally, the study is applicable to both the health services and health IT arenas. It is relevant to the health services literature because it acknowledges the importance of a whole-person approach to care. Likewise, it is relevant to health IT because it considers the role of technology in delivering integrated care to patients with complex needs.

\section{Conclusions}

Patients with behavioral health conditions are readmitted to the hospital 30 days after discharge at a higher rate than patients without behavioral health disorders. Several factors contribute to this pattern of overutilization. Existing regulations have traditionally restricted the exchange of behavioral health information unless the patient has given authorization at the person level, meaning that the specific person must be identified. The prevalence of suboptimal treatment outcomes for behavioral health patients with chronic illnesses indicates that it is necessary to commit more efforts to providing higher quality care to some of the most vulnerable patients.

Health care providers acknowledge that it is necessary to deliver holistic care to improve the quality of care and health-related outcomes for this subset of difficult-to-treat patients. This study contributes to our understanding of the potential role of HIEs in integrating the traditionally fragmented behavioral and general health service arenas.

\section{Acknowledgments}

The authors would like to thank Brian Yeaman, who shares the relevance and importance of behavioral health data exchange, for the support and guidance. The authors would also like to thank Darrell Burke for helping with the completion of this study. In addition, the authors would like to thank colleagues, friends, and subject matter experts who participated in the pilot testing of the survey instrument and interview protocol. This research did not receive any specific grant from funding agencies in the public, commercial, or not-for-profit sectors.

\section{Authors' Contributions}

RC and SF developed a conceptual framework for this study. RC collected and analyzed the quantitative and qualitative data and created a joint display for the quantitative and qualitative findings with meta-inferences. SF served as the subject matter expert 
on HIEs, helped to develop the quantitative survey, and provided general project oversights. NI guided the selection and implementation of the mixed methods approach and facilitated the creation of the joint display. NI and SF assisted with the development of the qualitative interview guide. AH made substantial contributions to the framing of the study and emphasized the relevance of the findings to existing policies and regulations. WOA assisted with quantitative data analysis and the creation of tables and figures for the manuscript. All authors (RC, SF, NI, AH, and WOA) contributed to the writing and editing of the manuscript.

\section{Conflicts of Interest}

None declared.

\section{Multimedia Appendix 1}

Survey prompt and questionnaire items.

[DOCX File, 17 KB-Multimedia Appendix 1]

\section{Multimedia Appendix 2}

Interview questions.

[DOCX File, 15 KB-Multimedia Appendix 2]

\section{Multimedia Appendix 3}

Measurement model.

[PNG File, 169 KB-Multimedia Appendix 3]

\section{Multimedia Appendix 4}

Themes and quotes from qualitative interviews (phase 2).

[DOCX File, 14 KB-Multimedia Appendix 4]

\section{Multimedia Appendix 5}

Joint display of quantitative and qualitative findings with meta-inferences.

[DOCX File, 19 KB-Multimedia Appendix 5]

\section{References}

1. Davis M, Balasubramanian BA, Waller E, Miller BF, Green LA, Cohen DJ. Integrating behavioral and physical health care in the real world: early lessons from advancing care together. J Am Board Fam Med 2013;26(5):588-602 [FREE Full text] [doi: 10.3122/jabfm.2013.05.130028] [Medline: 24004711]

2. Mechanic D. Seizing opportunities under the Affordable Care Act for transforming the mental and behavioral health system. Health Aff (Millwood) 2012 Feb;31(2):376-382. [doi: 10.1377/hlthaff.2011.0623] [Medline: 22323168]

3. Farmanova E, Baker G, Cohen D. Combining integration of care and a population health approach: a scoping review of redesign strategies and interventions, and their impact. Int J Integr Care 2019 Apr 11;19(2):5 [FREE Full text] [doi: 10.5334/ijic.4197] [Medline: $\underline{30992698]}$

4. American Hospital Association. Bringing behavioral health into the care continuum: opportunities to improve quality, costs and outcomes. American Hospital Association. 2012. URL: https://www.aha.org/guidesreports/

2012-01-20-bringing-behavioral-health-care-continuum-opportunities-improve-quality [accessed 2017-06-10]

5. Miller JE, Glover RW, Gordon SY. Crossing the behavioral health digital divide: the role of health information technology in improving care for people with behavioral health conditions in state behavioral health systems. National Association of State Mental Health Program Directors. 2014. URL: https://docplayer.net/

9632568-Crossing-the-behavioral-health-digital-divide.html [accessed 2017-07-15]

6. Cifuentes M, Davis M, Fernald D, Gunn R, Dickinson P, Cohen DJ. Electronic health record challenges, workarounds, and solutions observed in practices integrating behavioral health and primary care. J Am Board Fam Med 2015 Oct;28 Suppl 1:63-72 [FREE Full text] [doi: 10.3122/jabfm.2015.S1.150133] [Medline: 26359473]

7. Steinberg J, Daniel Jr JW. Depression as a major mental health problem for the behavioral health care industry. J Health Sci Manag Pub Health. 2020. URL: http://www.medportal.ge/journal/2003/volume4 n1/deppresione.pdf [accessed 2021-05-19]

8. Crowley RA, Kirschner N, Health and Public Policy Committee of the American College of Physicians. The integration of care for mental health, substance abuse, and other behavioral health conditions into primary care: executive summary of an American College of Physicians position paper. Ann Intern Med 2015 Aug 18;163(4):298-299. [doi: 10.7326/M15-0510] [Medline: 26121401] 
9. Kutlubaev MA, Hackett ML. Part II: predictors of depression after stroke and impact of depression on stroke outcome: an updated systematic review of observational studies. Int J Stroke 2014 Dec 26;9(8):1026-1036. [doi: 10.1111/ijs.12356] [Medline: 25156411]

10. Shi Y, Yang D, Zeng Y, Wu W. Risk factors for post-stroke depression: a meta-analysis. Front Aging Neurosci 2017 Jul 11;9:218 [FREE Full text] [doi: 10.3389/fnagi.2017.00218] [Medline: 28744213]

11. Thayabaranathan T, Andrew NE, Kilkenny MF, Stolwyk R, Thrift AG, Grimley R, et al. Factors influencing self-reported anxiety or depression following stroke or TIA using linked registry and hospital data. Qual Life Res 2018 Dec 4;27(12):3145-3155. [doi: 10.1007/s11136-018-1960-y] [Medline: 30078162]

12. Goodell S, Druss B, Walker E. Mental disorders and medical comorbidity. Robert Wood Johnson Foundation. 2011. URL: https://www.rwjf.org/en/library/research/2011/02/mental-disorders-and-medical-comorbidity.html [accessed 2018-02-10]

13. Office of the National Coordinator for Health Information Technology. URL: https://www.healthit.gov/ [accessed 2019-03-08]

14. Wu L, Ghitza UE, Zhu H, Spratt S, Swartz M, Mannelli P. Substance use disorders and medical comorbidities among high-need, high-risk patients with diabetes. Drug Alcohol Depend 2018 May 01;186:86-93 [FREE Full text] [doi: 10.1016/j.drugalcdep.2018.01.008] [Medline: 29554592]

15. Cheung S, Spaeth-Rublee B, Shalev D, Li M, Docherty M, Levenson J, et al. A model to improve behavioral health integration into serious illness care. J Pain Symptom Manage 2019 Sep;14(3):503-514. [doi:

10.1016/j.jpainsymman.2019.05.017] [Medline: $\underline{31175941]}$

16. Schiefelbein EL, Olson JA, Moxham JD. Patterns of health care utilization among vulnerable populations in Central Texas using data from a regional health information exchange. J Health Care Poor Underserved 2014 Feb;25(1):37-51. [doi: 10.1353/hpu.2014.0020] [Medline: 24509011]

17. Perrin J, Reimann B, Capobianco J, Wahrenberger JT, Sheitman BB, Steiner BD. A model of enhanced primary care for patients with severe mental illness. N C Med J 2018 Jul 10;79(4):240-244 [FREE Full text] [doi: 10.18043/ncm.79.4.240] [Medline: 29991617]

18. Germack HD, Caron A, Solomon R, Hanrahan NP. Medical-surgical readmissions in patients with co-occurring serious mental illness: a systematic review and meta-analysis. Gen Hosp Psychiatry 2018 Nov;55:65-71. [doi: 10.1016/j.genhosppsych.2018.09.005] [Medline: 30414592]

19. Desai MM, Rosenheck RA, Druss BG, Perlin JB. Mental disorders and quality of diabetes care in the veterans health administration. Am J Psychiatry 2002 Sep;159(9):1584-1590. [doi: 10.1176/appi.ajp.159.9.1584] [Medline: 12202281]

20. Druss BG, Rosenheck RA, Desai MM, Perlin JB. Quality of preventive medical care for patients with mental disorders. Med Care 2002 Feb;40(2):129-136. [doi: 10.1097/00005650-200202000-00007] [Medline: 11802085]

21. Alakeson V, Frank RG, Katz RE. Specialty care medical homes for people with severe, persistent mental disorders. Health Aff (Millwood) 2010 May;29(5):867-873. [doi: 10.1377/hlthaff.2010.0080] [Medline: 20439873]

22. Weinstein LC, Stefancic A, Cunningham AT, Hurley KE, Cabassa LJ, Wender RC. Cancer screening, prevention, and treatment in people with mental illness. CA Cancer J Clin 2016 Dec 10;66(2):134-151 [FREE Full text] [doi: 10.3322/caac.21334] [Medline: 26663383]

23. Compton MT, Manseau MW, Dacus H, Wallace B, Seserman M. Chronic disease screening and prevention activities in mental health clinics in New York state: current practices and future opportunities. Community Ment Health J 2020 May 4;56(4):717-726. [doi: 10.1007/s10597-019-00532-3] [Medline: 31902049]

24. Sporinova B, Manns B, Tonelli M, Hemmelgarn B, MacMaster F, Mitchell N, et al. Association of mental health disorders with health care utilization and costs among adults with chronic disease. JAMA Netw Open 2019 Aug 02;2(8):e199910 [FREE Full text] [doi: 10.1001/jamanetworkopen.2019.9910] [Medline: 31441939]

25. Schwenk TL. Comorbid mental illness is associated with doubled healthcare costs in patients with chronic disease. NEJM Journal Watch. 2019. URL: https://www.jwatch.org/na49812/2019/08/29/ comorbid-mental-illness-associated-with-doubled-healthcare [accessed 2020-05-15]

26. Benzer JK, Singer SJ, Mohr DC, McIntosh N, Meterko M, Vimalananda VG, et al. Survey of patient-centered coordination of care for diabetes with cardiovascular and mental health comorbidities in the Department of Veterans Affairs. J Gen Intern Med 2019 May 16;34(Suppl 1):43-49 [FREE Full text] [doi: 10.1007/s11606-019-04979-8] [Medline: 31098975]

27. Wulsin L, Pinkhasov A, Cunningham C, Miller L, Smith A, Oros S. Innovations for integrated care: The Association of Medicine and Psychiatry recognizes new models. Gen Hosp Psychiatry 2019 Nov;61:90-95. [doi:

10.1016/j.genhosppsych.2019.04.007] [Medline: 31104827]

28. Callan K, Fuller J, Galterio L, Just B, Reich K, Steigerwald C, et al. Making health information exchange work. J AHIMA 2014;85(11):32-36. [Medline: 25682655]

29. Hu LL, Sparenborg S, Tai B. Privacy protection for patients with substance use problems. Subst Abuse Rehabil 2011;2:227-233 [FREE Full text] [doi: 10.2147/SAR.S27237] [Medline: 24474860]

30. Druss BG, Mauer BJ. Health care reform and care at the behavioral health--primary care interface. Psychiatr Serv 2010 Nov;61(11):1087-1092. [doi: 10.1176/ps.2010.61.11.1087] [Medline: 21041346]

31. Vest JR, Gamm LD. Health information exchange: persistent challenges and new strategies. J Am Med Inform Assoc 2010;17(3):288-294 [FREE Full text] [doi: 10.1136/jamia.2010.003673] [Medline: 20442146] 
32. Bates DW, Bitton A. The future of health information technology in the patient-centered medical home. Health Aff (Millwood) 2010 Apr;29(4):614-621. [doi: 10.1377/hlthaff.2010.0007] [Medline: 20368590]

33. Vest J, Kern L, Silver M, Kaushal R, HITEC investigators. The potential for community-based health information exchange systems to reduce hospital readmissions. J Am Med Inform Assoc 2015 Mar;22(2):435-442. [doi:

10.1136/amiajnl-2014-002760] [Medline: 25100447]

34. Chen M, Guo S, Tan X. Does health information exchange improve patient outcomes? Empirical evidence from Florida hospitals. Health Aff (Millwood) 2019 Feb;38(2):197-204. [doi: 10.1377/hlthaff.2018.05447] [Medline: 30715992]

35. Golden RL, Emery-Tiburcio EE, Post S, Ewald B, Newman M. Connecting social, clinical, and home care services for persons with serious illness in the community. J Am Geriatr Soc 2019 May 10;67(S2):412-418. [doi: 10.1111/jgs.15900] [Medline: 31074858]

36. Campbell AN, McCarty D, Rieckmann T, McNeely J, Rotrosen J, Wu L, et al. Interpretation and integration of the federal substance use privacy protection rule in integrated health systems: a qualitative analysis. J Subst Abuse Treat 2019 Feb;97:41-46 [FREE Full text] [doi: 10.1016/j.jsat.2018.11.005] [Medline: 30577898]

37. Falconer E, Kho D, Docherty JP. Use of technology for care coordination initiatives for patients with mental health issues: a systematic literature review. Neuropsychiatr Dis Treat 2018;14:2337-2349 [FREE Full text] [doi: $\underline{10.2147 / \text { NDT.S172810] }}$ [Medline: 30254446]

38. Schmidt EM, Behar S, Barrera A, Cordova M, Beckum L. Potentially preventable medical hospitalizations and emergency department visits by the behavioral health population. J Behav Health Serv Res 2018 Jul 13;45(3):370-388. [doi: 10.1007/s11414-017-9570-y] [Medline: 28905296]

39. Bradford DW, Cunningham NT, Slubicki MN, McDuffie JR, Kilbourne AM, Nagi A, et al. An evidence synthesis of care models to improve general medical outcomes for individuals with serious mental illness. J Clin Psychiatry 2013 Aug 15;74(08):754-764. [doi: 10.4088/jcp.12r07666]

40. Annamalai A, Staeheli M, Cole RA, Steiner JL. Establishing an integrated health care clinic in a community mental health center: lessons learned. Psychiatr Q 2018 Mar 30;89(1):169-181. [doi: 10.1007/s11126-017-9523-x] [Medline: 28664447]

41. Shank N. Behavioral health providers' beliefs about health information exchange: a statewide survey. J Am Med Inform Assoc 2012 Jul;19(4):562-569 [FREE Full text] [doi: 10.1136/amiajnl-2011-000374] [Medline: 22184253]

42. Shen N, Sequeira L, Silver MP, Carter-Langford A, Strauss J, Wiljer D. Patient privacy perspectives on health information exchange in a mental health context: qualitative study. JMIR Ment Health 2019 Nov 13;6(11):e13306 [FREE Full text] [doi: 10.2196/13306] [Medline: 31719029]

43. Dwivedi YK, Rana NP, Chen H, Williams MD. A meta-analysis of the Unified Theory of Acceptance and Use of Technology (UTAUT). In: Governance and Sustainability in Information Systems. Managing the Transfer and Diffusion of IT. Berlin: Springer; 2011:155-170.

44. Kijsanayotin B, Pannarunothai S, Speedie SM. Factors influencing health information technology adoption in Thailand's community health centers: applying the UTAUT model. Int J Med Inform 2009 Jun;78(6):404-416. [doi:

10.1016/j.ijmedinf.2008.12.005] [Medline: 19196548]

45. Venkatesh V, Morris MG, Davis GB, Davis FD. User acceptance of information technology: toward a unified view. MIS Q 2003;27(3):425. [doi: 10.2307/30036540]

46. Slade EL, Dwivedi YK, Piercy NC, Williams MD. Modeling consumers' adoption intentions of remote mobile payments in the United Kingdom: extending UTAUT with innovativeness, risk, and trust. Psychol Mark 2015 Jul 07;32(8):860-873. [doi: 10.1002/mar.20823]

47. Rogers EM. Diffusion of Innovations, 4th Edition. New York: Free Press; 1995:1-518.

48. Rogers EM. Diffusion of preventive innovations. Addict Behav 2002 Nov;27(6):989-993. [doi: 10.1016/s0306-4603(02)00300-3]

49. Ivankova NV, Creswell J, Stick S. Using mixed-methods sequential explanatory design: from theory to practice. Field Methods 2016 Jul 21;18(1):3-20. [doi: 10.1177/1525822X05282260]

50. Subedi D. Explanatory sequential mixed method design as the third research community of knowledge claim. Am J Educ Res 2016;4(7):570-577 [FREE Full text] [doi: 10.12691/education-4-7-10]

51. Fornell C, Larcker DF. Evaluating structural equation models with unobservable variables and measurement error. J Mark Res 2018 Nov 28;18(1):39-50. [doi: 10.1177/002224378101800104]

52. Gefen D, Straub D, Boudreau M. Structural equation modeling and regression: guidelines for research practice. Commun Assoc Inf Syst 2000;4(7):A. [doi: 10.17705/1CAIS.00407]

53. Nunnally J, Bernstein I. Psychometric Theory. New York: McGraw-Hill Education; 1993:1-784.

54. Haenlein M, Kaplan AM. A beginner's guide to partial least squares analysis. Understand Sta 2004 Nov;3(4):283-297. [doi: 10.1207/s15328031us0304 4]

55. Henseler J, Ringle CM, Sinkovics RR. The use of partial least squares path modeling in international marketing. Adv Int Mark 2009;20:277-319. [doi: 10.1108/S1474-7979(2009)0000020014]

56. Hair JF, Ringle CM, Sarstedt M. PLS-SEM: indeed a silver bullet. J Mark Theory Prac 2014 Dec 08;19(2):139-152. [doi: 10.2753/mtp1069-6679190202] 
57. Kazár K. PLS path analysis and its application for the examination of the psychological sense of a brand community. Procedia Econ Financ 2014;17:183-191. [doi: 10.1016/s2212-5671(14)00893-4]

58. Sarstedt M, Ringle CM, Henseler J, Hair JF. On the emancipation of PLS-SEM: a commentary on Rigdon (2012). Long Range Plann 2014 Jun;47(3):154-160. [doi: 10.1016/j.lrp.2014.02.007]

59. Creswell JW. Qualitative Inquiry and Research Design: Choosing Among Five Approaches. Thousand Oaks, California, United States: Sage Publications Inc; 2012:1-472.

60. Clarke V, Braun V. Using thematic analysis in counselling and psychotherapy research: a critical reflection. Couns Psychother Res 2018 Mar 31;18(2):107-110. [doi: 10.1002/capr.12165]

61. Barnett J, Vasileiou K, Djemil F, Brooks L, Young T. Understanding innovators' experiences of barriers and facilitators in implementation and diffusion of healthcare service innovations: a qualitative study. BMC Health Serv Res 2011 Dec 16;11(1):342 [FREE Full text] [doi: 10.1186/1472-6963-11-342] [Medline: 22176739]

62. Onwuegbuzie AJ, Leech NL. Validity and qualitative research: an oxymoron? Qual Quant 2006 May 25;41(2):233-249. [doi: $10.1007 / \mathrm{s} 11135-006-9000-3]$

63. Guetterman TC, Fetters MD, Creswell JW. Integrating quantitative and qualitative results in health science mixed methods research through joint displays. Ann Fam Med 2015 Nov 09;13(6):554-561 [FREE Full text] [doi: 10.1370/afm.1865] [Medline: 26553895]

64. Rutherford GS, Hair JF, Anderson RE, Tatham RL. Multivariate data analysis with readings. J Royal Stat Soc - Series D (The Statistician) 1988;37(4/5):484. [doi: 10.2307/2348783]

65. Elkaseh AM, Wong KW, Fung CC. Perceived ease of use and perceived usefulness of social media for e-learning in libyan higher education: a structural equation modeling analysis. Int J Inf Educ Technol 2016;6(3):192-199. [doi: 10.7763/ijiet.2016.v6.683]

66. Schaper LK, Pervan GP. ICT and OTs: a model of information and communication technology acceptance and utilisation by occupational therapists. Int J Med Inform 2007 Jun;76 Suppl 1:212-221. [doi: 10.1016/j.ijmedinf.2006.05.028] [Medline: 16828335]

67. Ifinedo P. Understanding information systems security policy compliance: an integration of the theory of planned behavior and the protection motivation theory. Comput Secur 2012 Feb;31(1):83-95. [doi: 10.1016/j.cose.2011.10.007]

68. Alaiad A, Zhou L. Patients' behavioral intention toward using healthcare robots. URL: https://tinyurl.com/5xkbcja9 [accessed 2020-11-09]

69. Hsieh P. Physicians' acceptance of electronic medical records exchange: an extension of the decomposed TPB model with institutional trust and perceived risk. Int J Med Inform 2015 Jan;84(1):1-14. [doi: 10.1016/j.ijmedinf.2014.08.008] [Medline: 25242228]

70. Ranallo PA, Kilbourne AM, Whatley AS, Pincus HA. Behavioral health information technology: from chaos to clarity. Health Aff (Millwood) 2016 Jun 01;35(6):1106-1113. [doi: 10.1377/hlthaff.2016.0013] [Medline: 27269029]

71. Grando MA, Murcko A, Mahankali S, Saks M, Zent M, Chern D, et al. A study to elicit behavioral health patients' and providers' opinions on health records consent. J Law Med Ethics 2017 Jun 14;45(2):238-259 [FREE Full text] [doi: 10.1177/1073110517720653] [Medline: $\underline{30976154]}$

72. Druss BG, Rohrbaugh RM, Levinson CM, Rosenheck RA. Integrated medical care for patients with serious psychiatric illness: a randomized trial. Arch Gen Psychiatry 2001 Sep 01;58(9):861-868. [doi: 10.1001/archpsyc.58.9.861] [Medline: $\underline{11545670]}$

73. Unützer J, Katon W, Callahan CM, Williams JW, Hunkeler E, Harpole L, IMPACT (Improving Mood-Promoting Access to Collaborative Treatment) Investigators. Collaborative care management of late-life depression in the primary care setting: a randomized controlled trial. J Am Med Assoc 2002 Dec 11;288(22):2836-2845. [doi: 10.1001/jama.288.22.2836] [Medline: 12472325]

74. Alexopoulos GS, Reynolds III CF, Bruce ML, Katz IR, Raue PJ, Mulsant BH, PROSPECT Group. Reducing suicidal ideation and depression in older primary care patients: 24-month outcomes of the PROSPECT study. Am J Psychiatry 2009 Aug;166(8):882-890 [FREE Full text] [doi: 10.1176/appi.ajp.2009.08121779] [Medline: 19528195]

75. What is integrated care? SAMHSA-HRSA Center for Integrated Health Solutions (CIHS). URL: https://www.samhsa.gov/ integrated-health-solutions [accessed 2020-12-10]

76. Alexander GC, Stoller KB, Haffajee RL, Saloner B. An epidemic in the midst of a pandemic: opioid use disorder and COVID-19. Ann Intern Med 2020 Jul 07;173(1):57-58. [doi: 10.7326/m20-1141]

77. Kock N, Hadaya P. Minimum sample size estimation in PLS-SEM: the inverse square root and gamma-exponential methods. Info Systems J 2016 Nov 29;28(1):227-261. [doi: 10.1111/isj.12131]
Abbreviations
CFR: Code of Federal Regulations
DOI: diffusion of innovation
HIE: health information exchange
IT: information technology 
PLS-SEM: partial least squares structural equation modeling

UTAUT: unified theory of acceptance and use of technology

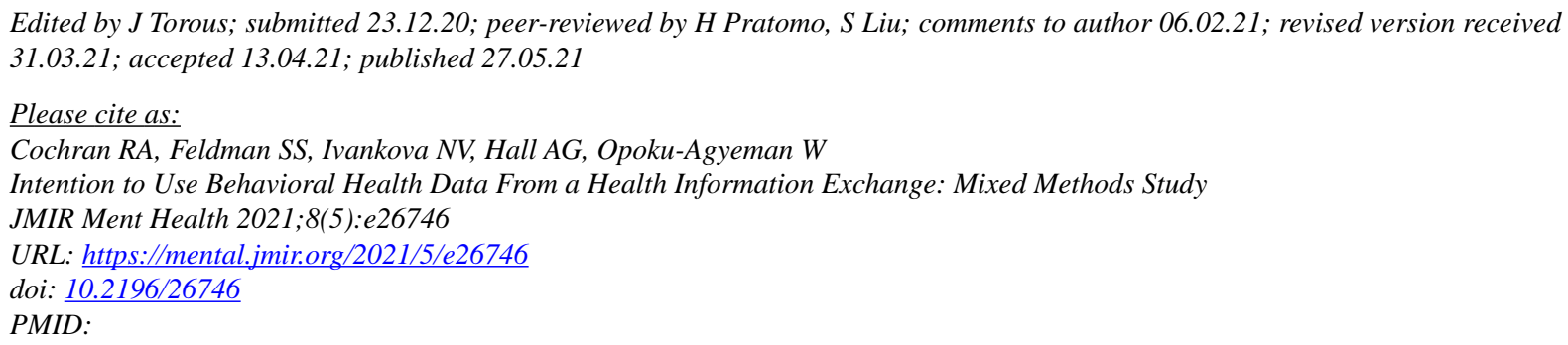

CRandyl A Cochran, Sue S Feldman, Nataliya V Ivankova, Allyson G Hall, William Opoku-Agyeman. Originally published in JMIR Mental Health (https://mental.jmir.org), 27.05.2021. This is an open-access article distributed under the terms of the Creative Commons Attribution License (https://creativecommons.org/licenses/by/4.0/), which permits unrestricted use, distribution, and reproduction in any medium, provided the original work, first published in JMIR Mental Health, is properly cited. The complete bibliographic information, a link to the original publication on https://mental.jmir.org/, as well as this copyright and license information must be included. 